\title{
Online mentoring and peer support: using learning technologies to facilitate entry into a community of practice
}

Lori Lockyer, John Patterson, Gregg Rowland and Doug Hearne University of Wollongong, Wollongong, NSW, Australia

email: lori_lockyer@uow.edu.au

A vital aspect of any professional education is the opportunity for students to engage in meaningful practical experiences. In pre-service teacher education in Australia, this vital teaching practice component has undergone challenges in recent years due to increasing student numbers (linked to the increasing demand for new teachers) and limited resources in university and school sectors. As such, initiatives to enhance the practical component of this professional degree have been sought. This paper details the methodology and outcomes associated with a pilot project that utilized asynchronous Web-based communication tools to facilitate mentoring and peer support through the teaching practice experience. Analysis of the online discussions and interviews with participants provides an indication of the nature of the interactions and the perceived value of the intervention, and informs the potential for larger-scale implementation.

\section{Introduction}

A vital aspect of any professional education is the opportunity for students to engage in meaningful practical experiences. For pre-service teachers, the teaching practice experience provides the opportunity to observe the pedagogical strategies and classroom management practices of experienced teachers; to apply theoretical concepts and practical skills in reallife settings; to speak the language of the profession in a real setting; and to understand the concept of the school community and the professional role of the teacher within that community.

Teaching practice has been an example of how teacher educators and practising teachers work together to mentor newcomers into the community of practice. However, the 
effectiveness of the implementation of this partnership model has been the discussion of recent debate and calls for reform in Australia (Ministerial Advisory Council on the Quality of Teaching, 1998; Ramsey, 2000). Changing fiscal and social influences require new approaches to be investigated.

The concerns of policy-makers are mirrored by the frustrations communicated by the active participants in the teaching practice experience (lecturers, pre-service and supervising teachers). University-based lecturers refer to limitations in discussing the application of theory into practice and providing counselling for pre-service teachers experiencing problems and anxieties when in the school setting. Further needs analysis with pre-service and supervising teachers suggests requirements for greater and more consistent communication among participants, access to a variety of information (related to the programme specifically and to the teaching profession generally) and access to resources and tools to support the teaching and learning process.

The affordances of information and communications technologies (ICTs) and their diffusion in primary, secondary and tertiary education setting allows for the exploration of innovative approaches to supporting the teaching practice experience. Networked technology provides the opportunity for students to have continued and frequent contact with faculty staff and other students thus supporting a philosophy of collaborative learning (Bruffee, 1993). The use of such technologies allows students to:

- share their practical learning experiences to develop a collective body of knowledge;

- discuss content material and their understanding of that content in the light of their practical experiences;

- engage in reflective practice that is valued by mentors and peers;

- develop a support network to facilitate ongoing information sharing;

- combat isolation through the development of a networked community that includes access to peers, mentors and resources (Naidu and Olsen, 1996).

This paper details the methodology and outcomes associated with a pilot project that utilized asynchronous Web-based communication tools to facilitate mentoring and peer support through the teaching practice experience. Content analysis provides an indication of the richness of the interactions possible in such technology-supported learning environments. In-depth interviews with lecturers and pre-service teachers provide a participant perspective on the value of the intervention and guidelines for large-scale implementation.

\section{The context}

The Faculty of Education in the University of Wollongong provides undergraduate preservice teacher education and postgraduate continuing and professional development. A specialized Bachelor of Education degree prepares secondary school physical and health education teachers, and graduates of this programme have gone on to positions in community health and recreation centres. This initial teacher preparation in physical and health education involves the development of discipline-based knowledge, curriculum and pedagogy skills and professional ethos. In each year of the four-year programme, pre- 
service teachers engage in school-based teaching practice experiences. This teaching practice is designed to provide students with the opportunity to put theory into practice.

Professional and educational literature expounds the benefits of the use of information and communications technologies (ICTs) in support of the roles and responsibilities of the physical and health educator (Milio, 1996; Committee on Enhancing the Internet for Health Applications, 2000). In 1998, with a strategic commitment and structuring of lecturing teams to include an appropriate mix of technology and physical and health education expertise, the programme began to integrate ICT use in discipline and pedagogybased subjects (Lockyer and Kerr, 2000; Lockyer, Patterson and Harper, 2001). The success of such implementations suggested that extensions of that integration might address the aforementioned challenges to the teaching practice programme. Of particular interest was how the online environment might facilitate the active process of reflection on the experience of professional practice through the interaction among the pre-service teachers and their university-based lecturers (Knights, 1985; Herrington, Herrington and Oliver, 1999).

\section{Pilot project}

A small-scale trial of online peer support and mentoring was implemented for students engaged in their final five-week teaching practice experience in July/August 2000. Ten fourth-year students volunteered to engage in the trial, with two lecturers acting as expert mentors.

A Website provided access to resources (such as links to sites related to syllabus topics and a lesson plan template) and a bulletin board, which facilitated the online interaction among students and lecturers. The bulletin board was structured to support specific topic exploration in order to provide:

- a general forum where students could interact on a more social level - not necessarily focusing on teaching practice issues;

- an activities forum where pairs of students were rostered weekly to submit an activity undertaken during the teaching practice;

- and a questions and problems forum where students could post any problems or queries they had in relation to their teaching practice or where lecturers could pose questions for the whole group.

One week prior to their school-based teaching practice experience, a two-hour training session was held with students and lecturers, which included an introduction to using the bulletin board system. A key aspect of this session was to clarify the students' tasks and responsibilities related to their participation in the online discussion. Similar attempts to support professional practice experience through online interaction have suggested use of an explicit structure to develop interaction (Brehm, 1999). Further, consideration was given to developing a structure that would facilitate the opportunity for all students to reflect upon and contribute their classroom experiences. Given that many participants had limited familiarity with online discussion, a roster structure was established. Each student was asked to contribute a description of one activity they had used or planned to use in the classroom during their teaching practice in an activities forum of the bulletin board during 
an assigned week. Students were responsible for providing feedback to their peers regarding these posted contributions.

All students were also given the opportunity to request advice from their peers and lecturers, as well as to suggest possible solutions to issues faced by other students during the teaching practice, on an ad hoc basis through the questions/problems forum of the bulletin board.

Lecturers were not given a defined task but were expected to monitor regularly all discussion forums and respond to students' questions and problems if it seemed that their peers could not help them resolve issues. Lecturers were also expected, if necessary, to stimulate online discussion by posing practice-based questions.

All postings to the three bulletin board forums were saved and analysed in order to understand the use patterns and nature of discussion that took place. Further, students' and lecturers' perspectives on the experience were elicited through post-implementation interviews which also provided explanatory support to the analysis of the interaction data. Interview questions covered issues related to participants' perceptions of the value of the online interaction in supporting the development of their practice-based skills and understanding, their discipline (that is, physical and health education) knowledge base, professional self-concept and teaching philosophy, and social/emotional encouragement as well as the technical considerations of using the online system. In addition to analysis of the pattern of postings, analysis of the nature of the online discussion was undertaken with consideration of these issues.

Analysis of the postings revealed that, while students had been assigned a week in which to post an example of teaching activities that they had used or intended to use in class, only four of the ten participants fulfilled this task. Of those, one student's initial contribution was limited to a description of an activity used with children in class. Probing questions posted by other students and a lecturer stimulated reflective responses from the initiator regarding the process and outcomes of engaging in the activity with the children. The other three students who initiated contributions during their assigned week focused on basic descriptions of an activity they planned to implement in class. Questions to elicit more information about the planned activity and/or sharing of personal experiences with similar situations were posted by other students. This provided the initiators with an opportunity to clarify their lesson plans and spark ideas for possible activities among the other participants. For example, in response to a description of a ball game one student intended to implement, another participant posted:

Great game! ... I will definitely be trying it with my year 7's next time we have prac. Only thing is I'm not $100 \%$ clear on is what the zone in the middle is for?!?!? Clarification please!!!!!

The general and questions/problems forums were by far the most utilized by the participants (26 postings in the activities forum, 67 postings in the questions/problems forum, and 206 postings in the general forum). Participants contributed practice-related issues and questions to both the generallproblems forums. However, the majority of the postings in the general forum covered more personal or social topics (such as jokes, birthday greetings, organization of social outings, etc.). 
The lecturers initiated discussion related to classroom practice (for example, strategies to engender respect from children) in the questions/problems forum within the first few days of the teaching practice in an attempt to welcome the students into this discussion space. However, students quickly took control of the discussion by sharing their classroom experiences, asking their peers and the lecturers for specific advice and providing their peers with practical suggestions and emotional encouragement. Practice-based topics discussed in the questions/problems and general forums included aspects of classroom management, planning for activities, reflection on practice and the process of teaching practice assessment. Questions posed by the lecturers and requests for advice from students engendered contributions of both conceptual understanding or philosophy of teaching practice as well as detailed description and reflection on specific strategies used in class by the students. One students' posting expressed emotional stress over the teaching practice situation:

Subject: Soul Searching

How do you get yourself out of a rut? I don't want to be here. I know i should plan but for the life of me, it just isn't happening ... there are soooo many things to think about and consider i simply can't be blessed starting ... What do I do ?!? My life sux ... Signed: Screwed up mind.

Four students responded to this posting with contributions of encouragement. For example, one student replied:

Subject: re: soul searching

... We are all new at this - we are trying to put the theory into practice, its tough man i understand the way your feelin bro ... you think that your not cut out for this stuff ... have a look around the staff room - do you see any of them up till all hours thinking of what they have to teach tomorrow - no. They have the experience, knowledge and resources and know how to use them efficiently and effectively. That's what we are here to learn and develop...

Just think about the good lessons or even just the good parts in the lessons, think of the information that the students have learnt - from you!!! Watch how their skills develop over the 5 weeks - because of you!!!

One of the lecturers used this set of postings to focus the discussion on the attributes of a professional teacher (an issue previously explored in lectures).

The pattern and nature of contributions suggests that a more free-flowing interaction rather than structured assignment of roles was appropriate to support the students' needs while they were engaged in their practice teaching experience. This observation was further confirmed through post-implementation interviews with participants who noted that an imposed structure of assigned contribution in the activities forum confined the interaction process and that they felt more comfortable contributing to the more open general or questions/problems forums.

\section{Extending the concept}

Lessons learnt from this initial small-scale trial provided a basis on which to structure subsequent implementations of online peer support and mentoring through the teaching practice experience. The 2001 cohort of fourth-year students were given the opportunity to 
participate in the online intervention during their five-week (July/August) teaching practice experience. For this implementation one forum was utilized with two threads - one for general or social issues and one for teaching issues. Unlike the previous implementation, a structure or roster for contributions was not imposed. While far fewer contributions were posted by this group $(n=106)$ than that from the previous cohort $(n=299)$, the nature of the discussion was similar. The limited participation may have been a factor of technical difficulties (individual student access to the Internet and University server downtime) combined with a smaller number of participants (seven versus ten).

The concept was also extended to include second-year students who were involved in one week of secondary school teaching practice in each of two semesters of the academic year (one week in May and one week in October). The seven fourth-year students agreed to act as online mentors for fourteen second-year students. Two second-year students were grouped with one fourth-year student acting as mentor.

One week prior to the commencement of the first teaching practice experience for the second-year students, the participants attended a training and development exercise. This session was used for groups to meet and negotiate times at which they expected to access the bulletin board over the week. Second-year students were advised that they could submit questions, problems and requests for advice. The fourth-year mentor was responsible for providing suggestions and feedback on the issues or questions raised by the second-year students undertaking their practice. Students were advised that the participating lecturers would monitor the discussions on a regular basis to ensure that questions or problems were not going unanswered (particularly in the event that a fourthyear mentor experienced technical difficulty accessing the bulletin board).

Analysis of the online interactions found that the nature of the discussion focused on general behaviour management issues with some practical teaching strategies being suggested by the mentors. When second-year students returned to campus after their teaching practice, all participants were invited to attend a session to discuss the online experience. The teaching practice students agreed that they appreciated knowing that there was someone online with whom they could share their successes and frustrations. They said that they felt comfortable asking their online mentors for advice and suggestions.

The online mentors felt that the experience allowed them to reflect on their previous practice teaching experiences. A comment by one mentor was wholeheartedly supported by the others: 'I was giving advice and I thought "where did that come from?" I can't believe how much I've learnt in the last three years!'

The second teaching practice for the second-year students occurred after the fourth-year online mentors had engaged in their own final practice teaching experience (five weeks in July/August). Preliminary analysis of the online interactions from the second teaching practice suggests that, in these discussions, the fourth-year mentors were far more explicit in their advice regarding teaching strategies. They made specific reference to examples of their experiences during their recent teaching practice and provided their analysis of the teaching strategies which they employed.

Whilst issues of technical stability of the bulletin board system and access to the site from schools needs further consideration, the opportunity to be involved in discussions both 
personal and professional over the duration of the teaching practice was rated highly and thought well worthwhile by all participants and therefore worthy of continuation.

\section{Conclusions}

The success of these small-scale trials has highlighted the potential for learning technologies to enhance the practical component of a pre-service teacher education programme and provides a foundation for a future, larger-scale implementation. The following issues must be considered and detailed.

\section{Structuring discussion and supporting reflection}

The initial attempt to elicit participation and facilitate reflective processes among the students via a roster of contributions regarding teaching activities was not successful. The pattern of discussion and feedback from students suggests a more free-flowing interaction to be beneficial. However, students' initial tendency to be descriptive (recounting what happened) needs to be extended by the other participants. Questioning and contribution of their own experiences by lecturers and other students facilitates the engagement of students in a more reflective process, discussing why it happened and what they would do differently next time. Preparing both the students and the lecturers to identify the difference between a descriptive and reflective posting and developing strategies to support reflection may need to become a focus of the pre-implementation training session. The lecturers' role has further importance in simulating discussion through practice-based questions, providing contributions that link the students' classroom experiences to campus-based lectures, and acting as a source of ideas or guidance.

\section{Communication Tools}

An asynchronous communication tool was selected based on benefits of flexibility of time for contribution and recording/reflection purposes. However, given that some groups of students choose to schedule their online meetings for a particular time, it may be appropriate to provide access to a synchronous tool such as a chat space which would better facilitate real-time interaction.

Future research associated with a large-scale implementation will provide empirical evidence for the extent to which this intervention prepares pre-service teachers for their future professional role.

\section{References}

Brehm, B. (1999), 'Factors for successful telementoring of preservice teachers', in Collis, B. and Oliver, R. (eds), Proceedings of ED-MEDIA99 World Conference on Educational Multimedia, Hypermedia and Telecommunications, Charlottesville, VA: Association for the Advancement of Computing in Education, 1300-1.

Bruffee, K. A. (1993), Collaborative Learning: Higher Education, Interdependence, and the Authority of Knowledge, Baltimore: The Johns Hopkins University Press.

Committee on Enhancing the Internet for Health Applications: Technical Requirements and Implementation Strategies, Computer Science and Telecommunications Board, National Research Council (2000), Networking Health: Prescriptions for the Internet, Washington: National Academy of Sciences. 
Goodlad, J. I. (1994), Educational Renewal: Better Teachers, Better Schools, San Francisco: Jossey Bass.

Herrington, T., Herrington, J. and Oliver. R. (1999), 'Providing reflective online support for preservice teachers on professional practice in schools', in B. Collis and R. Oliver (eds), Proceedings of ED-MEDIA99 World Conference on Educational Multimedia, Hypermedia and Telecommunications, Charlottesville, VA: Association for the Advancement of Computing in Education, 161-71.

Knights, S. (1985), 'Reflection and learning: the importance of a listener', in D. Boud, R. Keogh and D. Walker (eds), Reflection: Turning Experience into Learning, London: Kogan Page, 85-90.

Lockyer, L. and Kerr, Y. (2000). 'Learner as designer-producer: physical and health education students experience Web-based learning resource development', in J. Bourdeau and R. Heller (eds), Proceedings of ED-MEDIA2000 World Conference on Educational Multimedia, Hypermedia and Telecommunications, Charlottesville, VA: Association for the Advancement of Computing in Education, 591-5.

Lockyer, L., Patterson, J. and Harper, B. (2001), 'ICT in higher education: evaluating outcomes for health education', Journal of Computer Assisted Learning, 17 (3), 275-83.

Milio, N. (1996), Engines of Empowerment: Using Information Technology to Create Healthy Communities and Challenge Public Policy, Chicago: Health Administration Press.

Ministerial Advisory Council on the Quality of Teaching (1998), Towards Greater Professionalism: Teacher Educators, Teaching and the Curriculum, Sydney: New South Wales Department of Education and Training.

Naidu, S. and Olson, P. (1996), 'Making the most of practical experience in teacher education with computer-supported collaborative learning', International Journal of Educational Telecommunications, 2, 265-78.

Ramsey, G. (2000), Quality Matters: Revitalising Teaching: Critical Times Critical Choices; Report on the Review of Teacher Education, New South Wales, Sydney: New South Wales Department of Education and Training. 